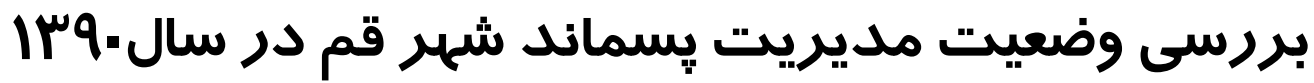

\author{
مهدى فرزادكيا'، حسين آذرى “"، احسان احمدى'، بابك كاكاوندى"،عماد دهقانى فردّ، شهرام نظرى'

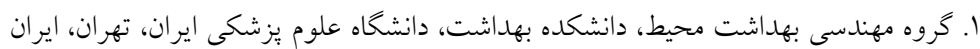

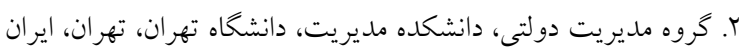

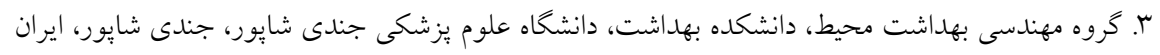

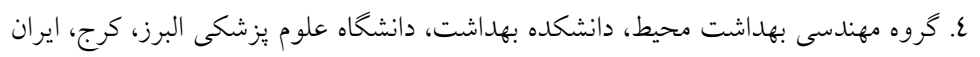

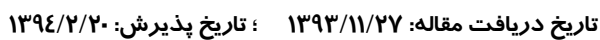

\section{جكيده}

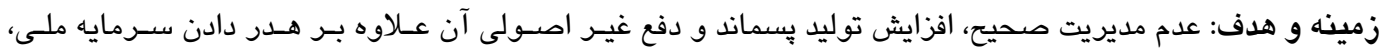

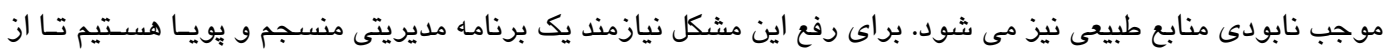

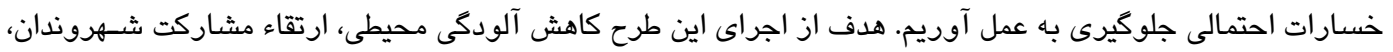

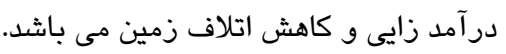

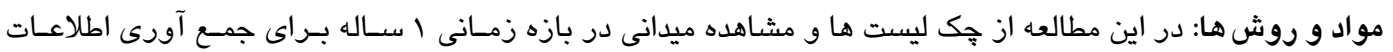

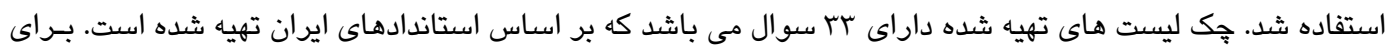

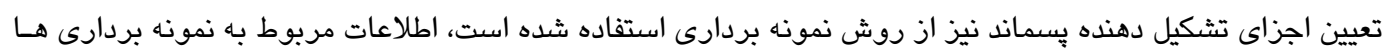

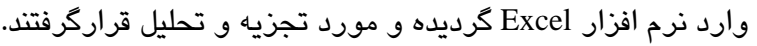

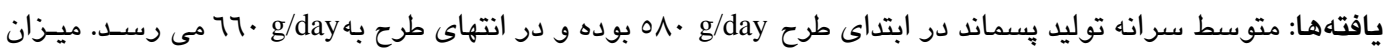

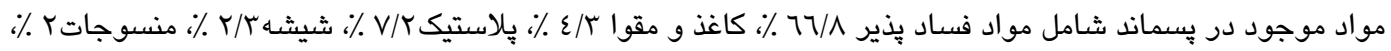

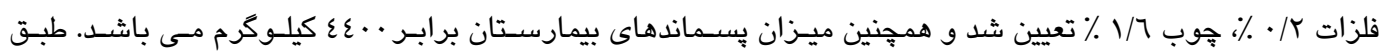

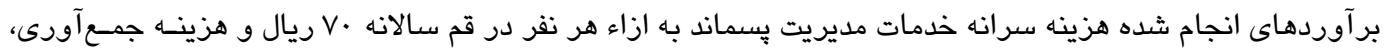

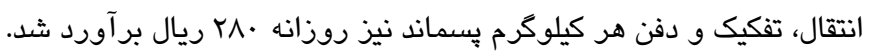

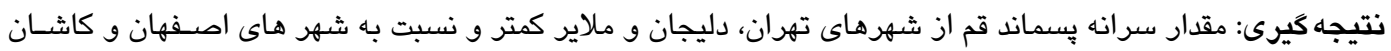

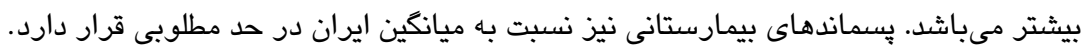

محيطى و آنجهه براى عموم مردم مورد توجه اسـت'. از ديسـكاه

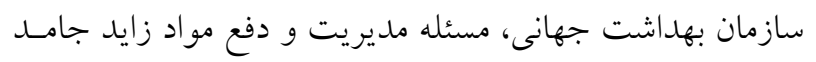

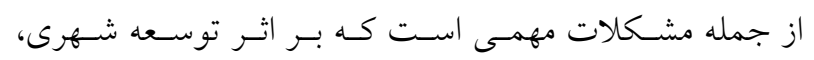

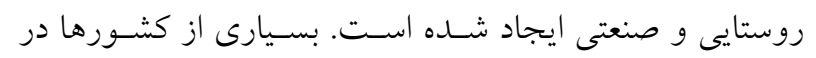

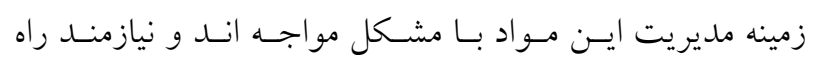

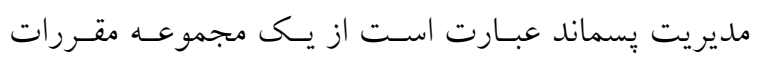

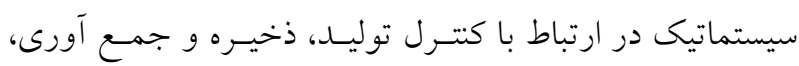

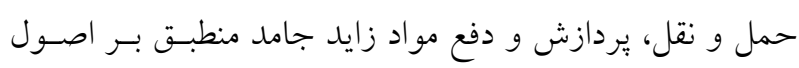

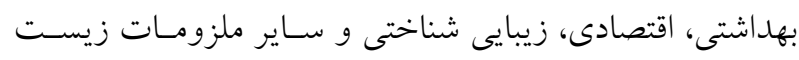


به جمع آورى و دفع صحيح يسماند باعـث ايجـاد بr مشـكل

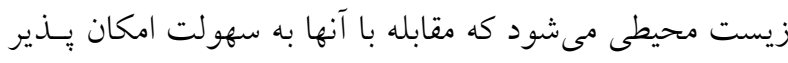
نمى باشد. ^همجنين عدم مديريت صحيح يسماند، سبب ايجـاد

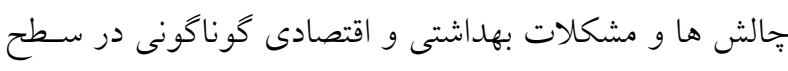

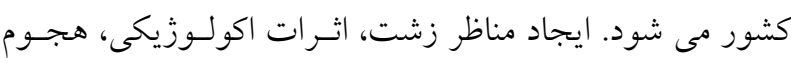

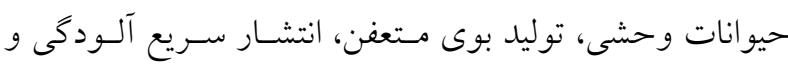

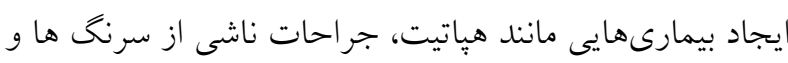

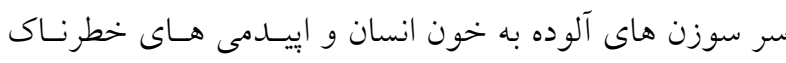

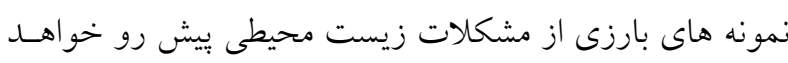

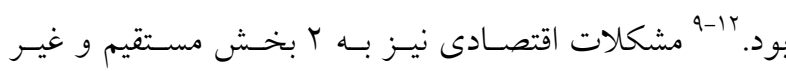

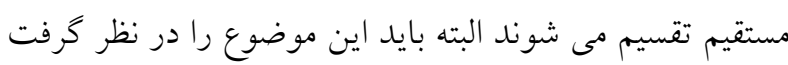

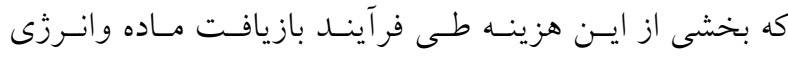

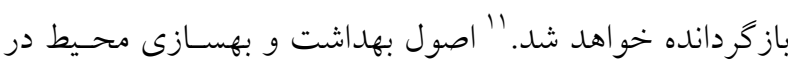

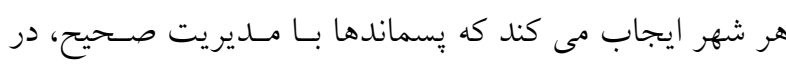

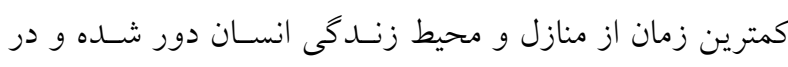

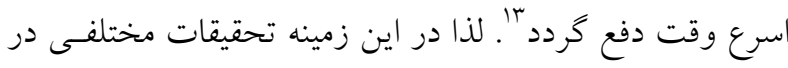

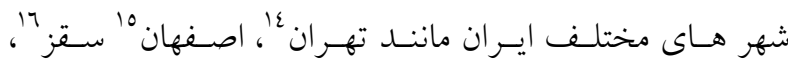

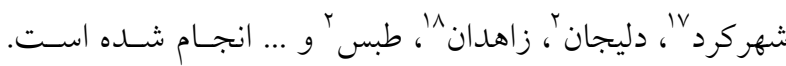

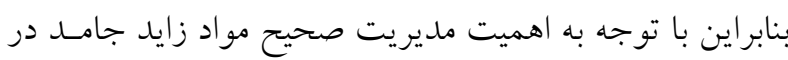

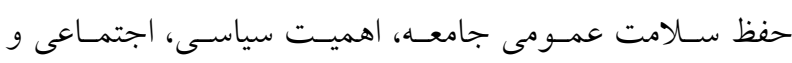

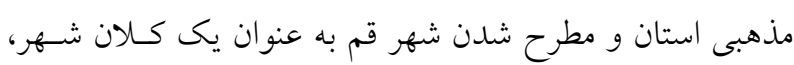

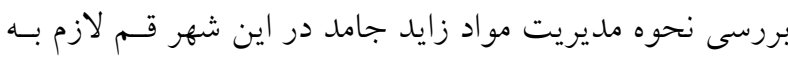

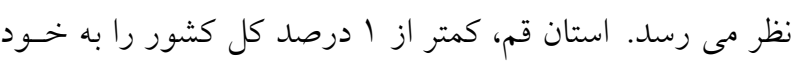

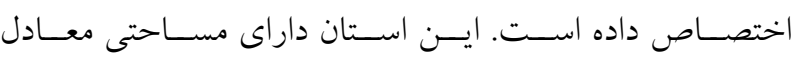

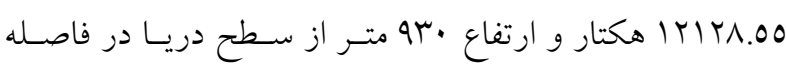

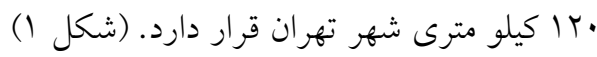

\section{مواد و روشها}

مطالعه صورت گرفته از نوع توصيفى -مقطعى مى باشد. طى روسى

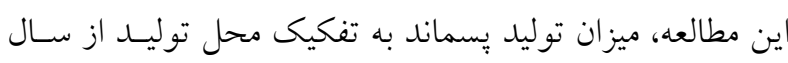

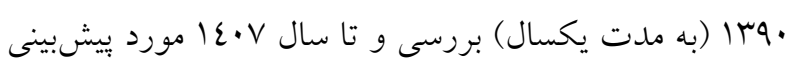

حلهاى جامع و كاربردى مى باشند. بر اساس دستورالعمل كار

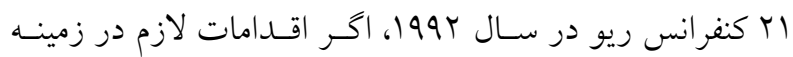

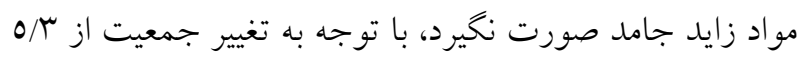

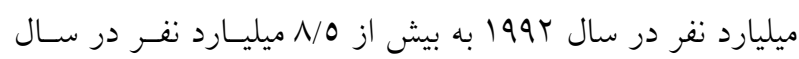

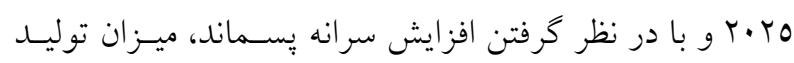

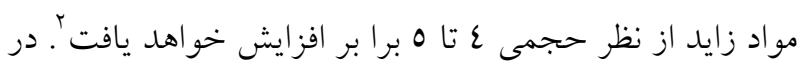

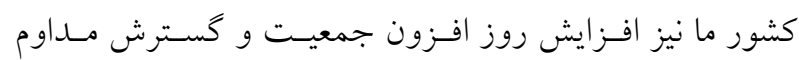

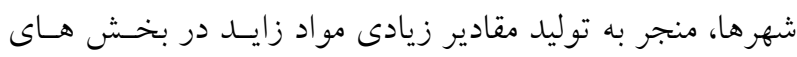

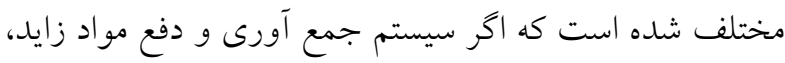

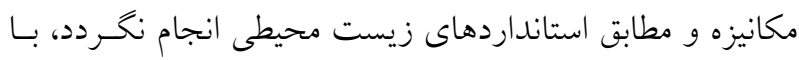

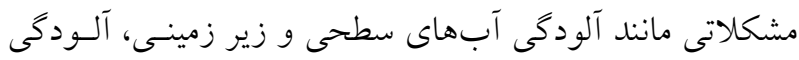

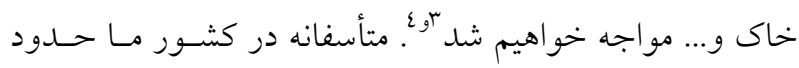

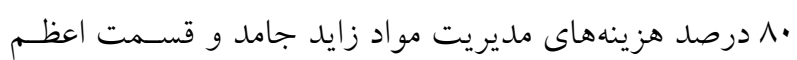

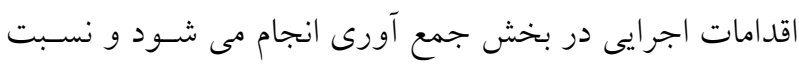

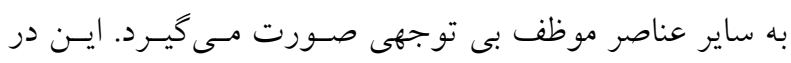

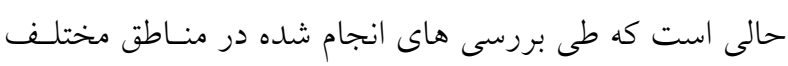

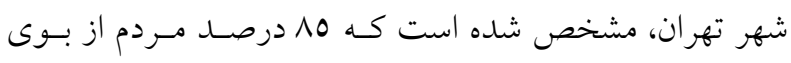

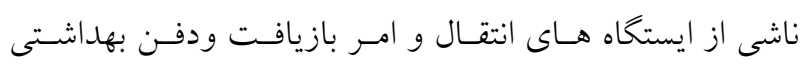

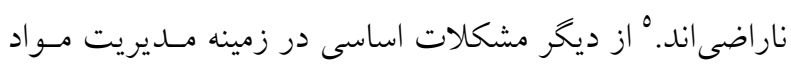

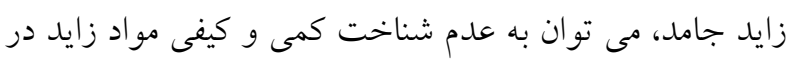

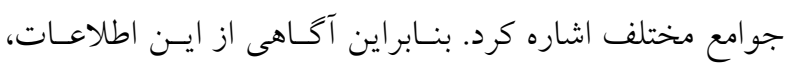

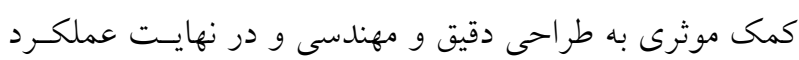

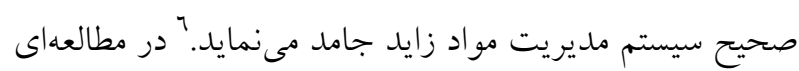

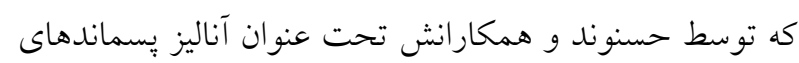

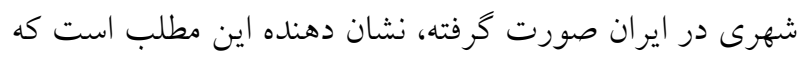

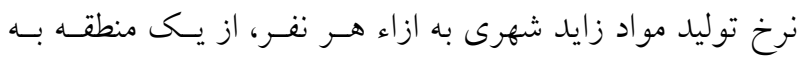

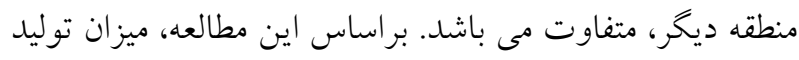

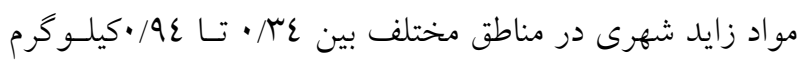

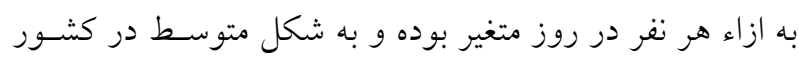

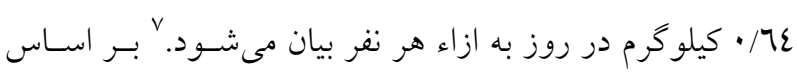

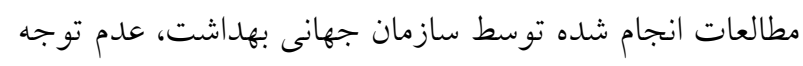


مناطق ع كانه استان قـم مـورد بررسـى و نمونسهـ بـــدارى قـرار

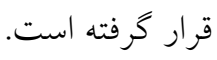

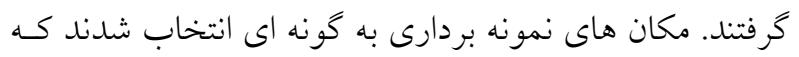

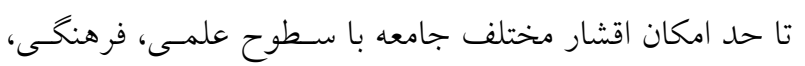

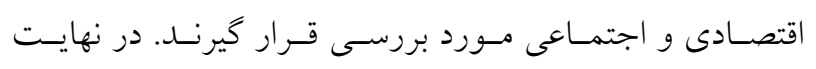

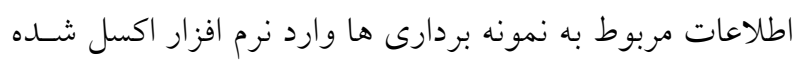
و مورد تجزيه و تحليل قرار خرفت.

\section{يافتهها}

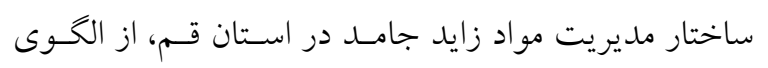

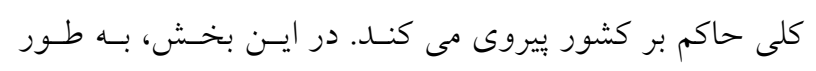

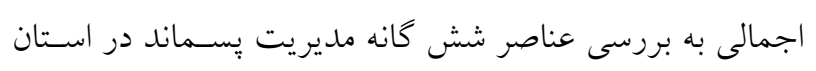

$$
\text { قم مى بردازيم. }
$$

\section{توليد}

توليد يسماند در شهر قم براساس فصول مختلف متنوع مى

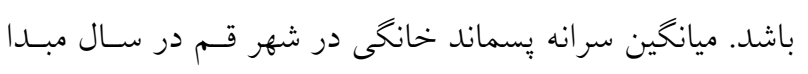

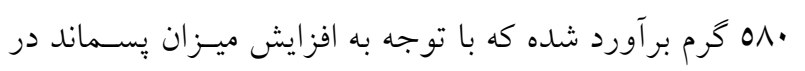

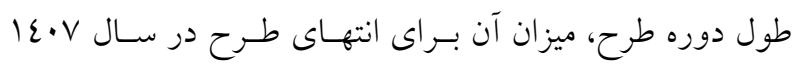

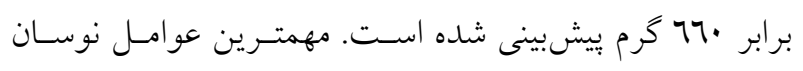

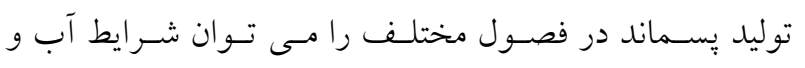

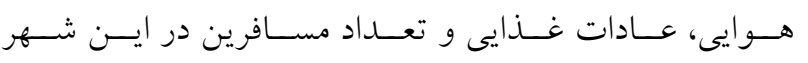

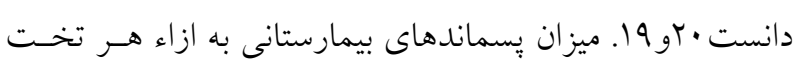

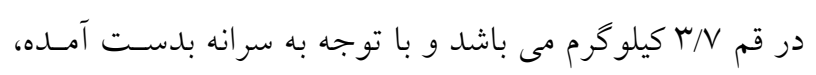

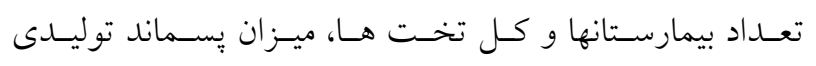

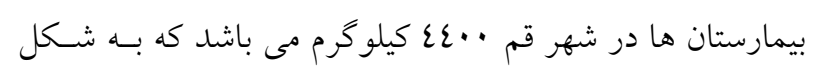

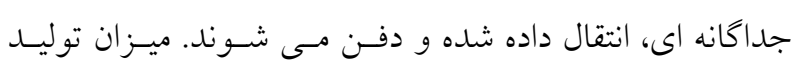
يسماند به تفكيك منبع توليد در جدول شماره آ آمده است.

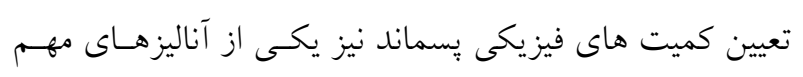

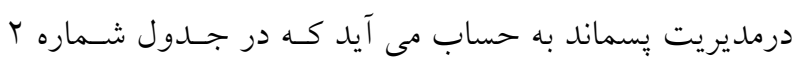
قابل مشاهده است. 
شهر قم به دو صورت خانه به خانه و به وسـيله ظـروف جمـع

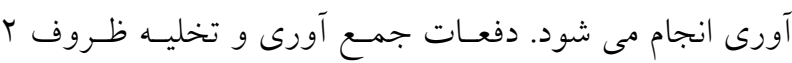
روز در هفته مى باشد، ولى در روزهاى گرم ايسن امـر هـر روز

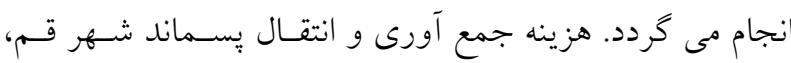
سالانه به بـيش از •7 ميليـارد ريـال مسى رســ كـه نسـبت بـــ شهرهاى ديخـر در سـطح نسـبتا بـالايى قـرار دارد. مــواد زايـــ توليدى در مناطق روباز، در طول روز به شكل نيمـه مكـانيزه و توسـط خــودرو هـاى نيسـان، خـاور برسـى، كـاميون برسىى جمع آورى مىشود. از سال سه، جمع آورى مواد زايد جامــ در شهر به صـورت شـبانه و راس سـاعت اب انجـام مسى شـود و ماموران بهداشـت موظـف هسـتند تـا قبـل از سـاعت V تمـام يسماندها را از سطح شـهر جمـع آورى نماينـد. تعـداد و نـوع وسايل مورد استفاده براى جمع آورى يسـماند در شـهر قـم در جدول شماره ب آمدهاست.

ذخيره سازى در محل

مرحله ذخيره سازى به ملت زمانى اطلاق مى شـود كـه ظـــف توسط ماموران برداشته و تخليه مى شود. وظيفه جابسه جـايى و ذخيرهسازى يُماند در محل، بـه عهـــه توليـد كنــده يسـماند

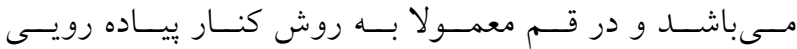
انجام مى گيرد. (CURB SIDE)

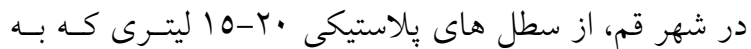
وسيله يِلاستيك مشكى رويوش شده، براى ذخيره و نخهـدارى

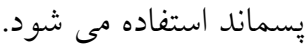

\section{جمع آورى}

در حال حاضر •م درصد از مواد زايد توليدى سـطح شـهر به صورت نيمه مكانيزه جمـع آورى مسىشـود. در مكـان هـاى قديمى شهر، به دليل وجود كو جهه هاى تنگ و باريك كه امكان تردود خودرو نمى باشد، از تجرخ هاى دستى بـهـ منظـور جمـع آورى يسماند استفاده مى شود. به شكل كلى، جمـع آورى در

جدول ا: ميزان يسماند در منابع مختلف توليد

\begin{tabular}{|c|c|c|c|c|c|}
\hline \multicolumn{5}{|c|}{ ميزان بسماند(تن در روز) } & \multirow[t]{2}{*}{ نوع منبع توليد } \\
\hline $1 \varepsilon \cdot V$ & $1 \varepsilon \cdot r$ & $1 \pi q V$ & Irar & $1 r q$. & \\
\hline $1 \cdot 7 \pi$ & $911 / r$ & $V \Lambda \cdot / r$ & $77 V / r$ & $O V \cdot / T$ & 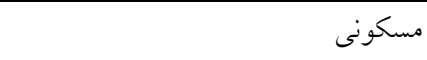 \\
\hline vo & זד & 00 & $\varepsilon V$ & $\varepsilon$ & 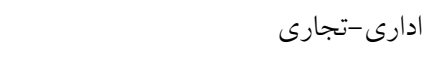 \\
\hline 17 & $1 \% / 0$ & $11 / \varepsilon$ & $9 / 0$ & $\wedge$ & 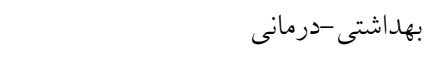 \\
\hline $1 \ldots$ & $9 \ldots$ & vo.. & $7 \ldots$ & $0 \ldots$ & 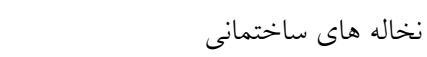 \\
\hline V & 7 & 0 & $\varepsilon$ & $r$ & يارى و فضاى سبز \\
\hline $11 \varepsilon 0$ & $9 \Lambda \cdot / r$ & $\Lambda \varepsilon \cdot / \Gamma$ & $\checkmark \backslash \Lambda / r$ & $71 \varepsilon / Y$ & كل بسماندها بدون احتساب نخاله هاى \\
\hline
\end{tabular}

جدولץ: آناليز كمى يسماند در فصول مختلف سال •q 1

\begin{tabular}{|c|c|c|c|c|c|c|c|c|c|c|c|}
\hline ساير & فلزات & لاستيك و و & منسوجات & خاكروبه & جوب & شيشه & پِلاستيك & كاغذ ومقوا & PET & مواد & فزول إسماند \\
\hline $9 / 1$ & $1 / 1$ & $\cdot / 20$ & $1 / \varepsilon$ & $\mathrm{V} / \mathrm{V}$ &.$/ 90$ & $r / \Lambda$ & $\mathrm{T} / \mathrm{V}$ & r/vo & $\cdot / \mathrm{VI}$ & $7 \% / 0$ & بهار \\
\hline$\varepsilon / V_{0}$ & $1 / 71$ & $\cdot / \Lambda$ &.$/ 10$ & $7 / \Lambda$ & $\cdot / \Lambda$ & $r / l$ & $T / V$ & $r / \varepsilon$ & $\cdot / 10$ & VT & تابستان \\
\hline$V / 10$ & r & $1 / 0$ & $1 / 90$ & $\varepsilon / 10$ & T/ro & $r / 7$ & $V$ & r/ro & $\cdot / 77$ & $77 / 0$ & پِيايز \\
\hline
\end{tabular}




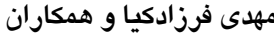

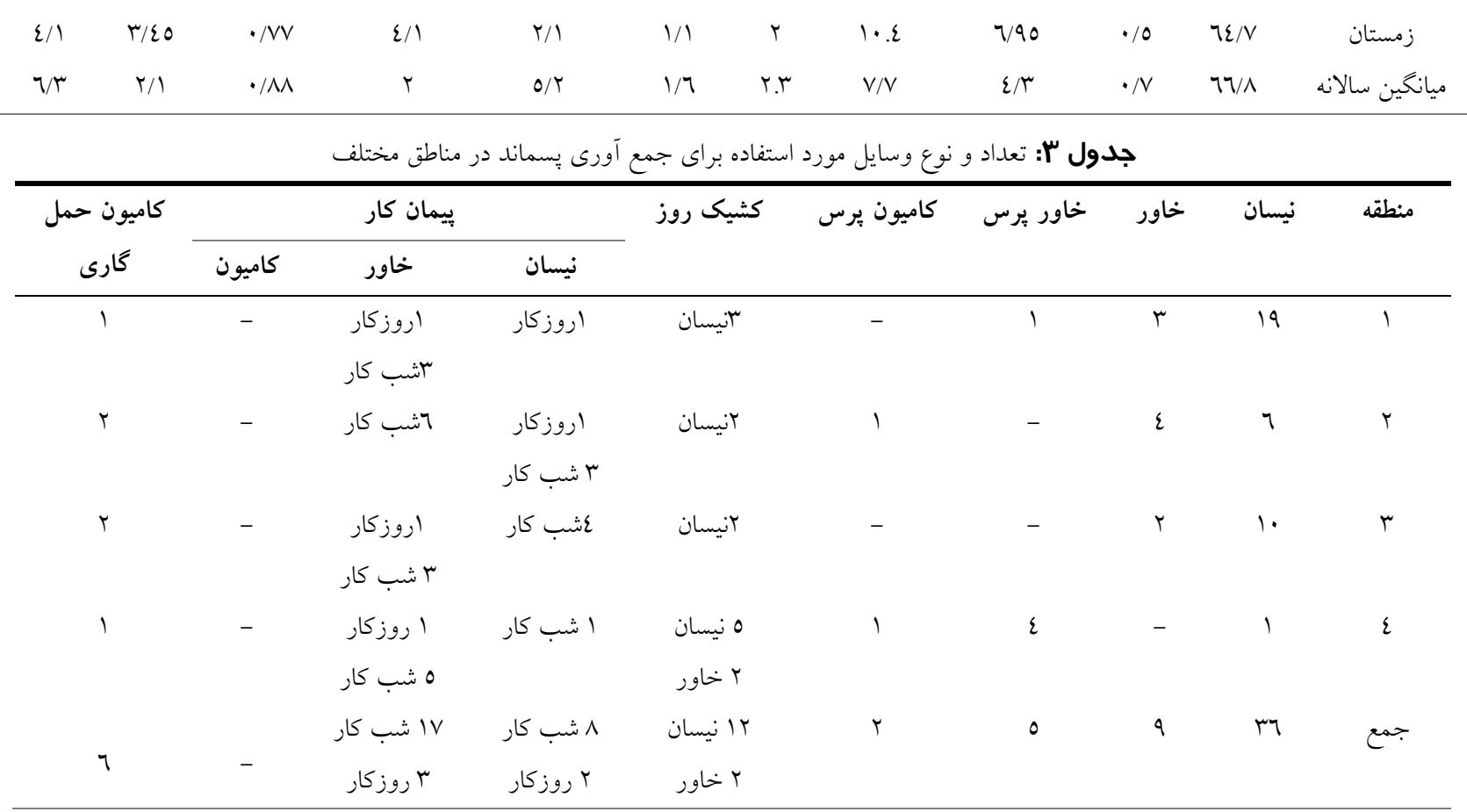

موجود مى باشد كه هنوز به شكل كامل كارايى ندارند.

وضعيت ايستخاههاى انتقال

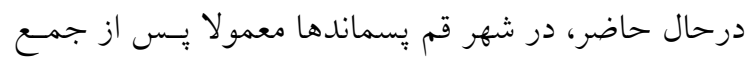

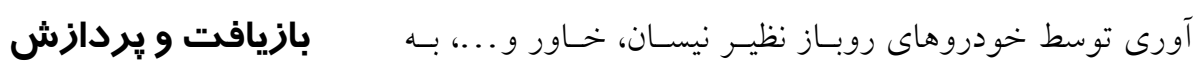

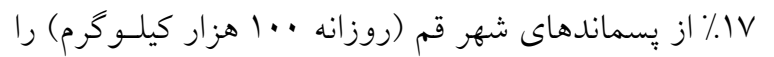

ايستخاه هاى موقت بارگيرى، منتقل و سبس توسط خودروهاى

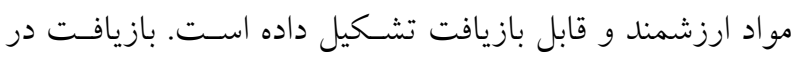

سنخين جهت دفن بهداشتى به سايت حلقه دره شهر كرج انتقال شهر قم، به دو روش تفكيك از مبدا و تفكيك در مقصد (مكان

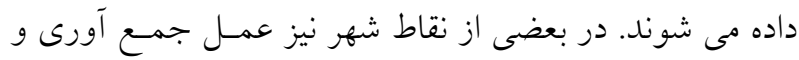

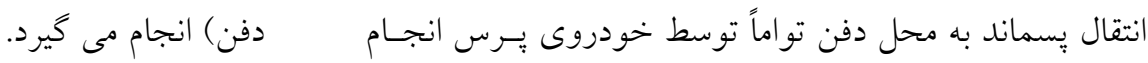

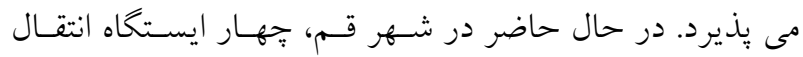
جدول ع: وزن و سود اقتصادى ناشى از بـماندهاى بازيافت شده

\begin{tabular}{|c|c|c|c|c|}
\hline حاصل از بازيافت & قيمت خالص & نرخ به ازاء هر كيلوكَرم & 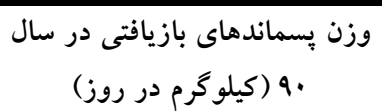 & اجزاء بسماند \\
\hline TITY. & TAY & rr. & $r l$. & PET \\
\hline$\varepsilon \mid r \wedge$. & Tr & 7. & $1 r q$. & كاغذ ومقوا \\
\hline orogr. & Tr & rq. & ו וזr. & يلاستيك \\
\hline 1011. & Tr & 0. & 79. & شيشه \\
\hline- & - & - & $\varepsilon \wedge$. & جوب* \\
\hline- & - & - & $7 .$. & منسوجات* \\
\hline- & - & - & $r 7 \varepsilon$ & جرم ولاستيك* \\
\hline
\end{tabular}


استفاده قرار گرفت. با توجه به مطالعات انجام شده در •r سال

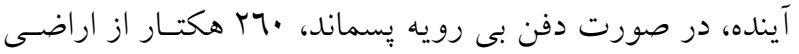
شهر قم از بين خواهد رفت.

\section{بحث}

توليد روزانه بسماند در شهر قم، به طور ميانگين بـين ..0

تا •70 تن و سرانه بسماند به ازاء هر نفر جيزى در حدود ..7

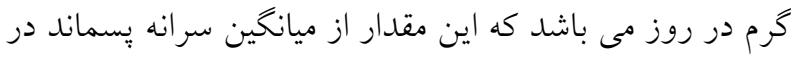

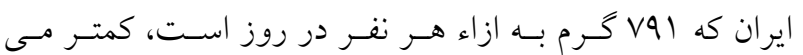

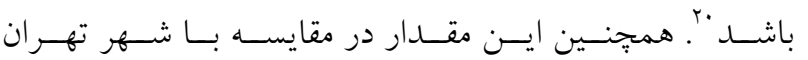

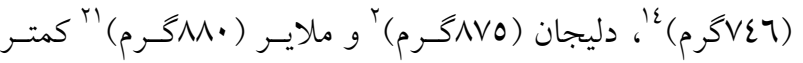

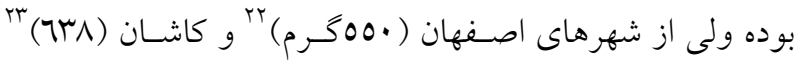

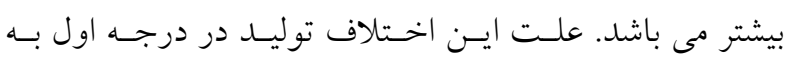

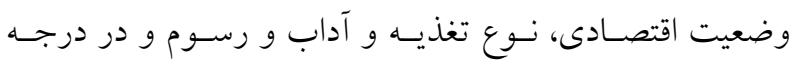
بعدى به تفاوت فرهنكى در اين شهـرها مـرتبط مسى شـود. در

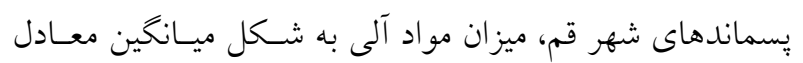

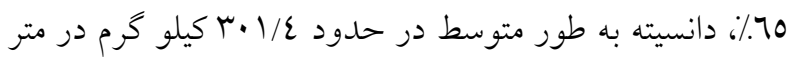

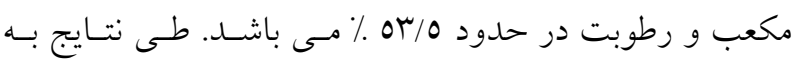

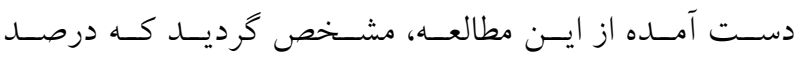

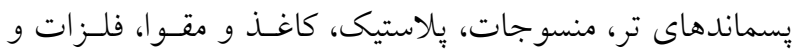

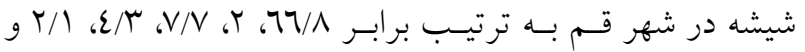

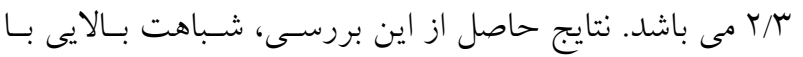

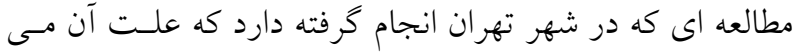
تواند به دليل شرايط جغرافيايى و اجتماعى نزديك اين دو شهر به يكديخر باشد. 'ا در مطالعه مشابهى كه در شهر وليس (كشور

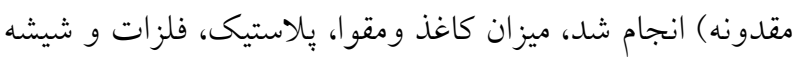

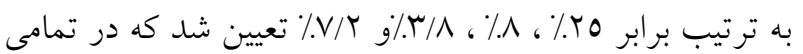

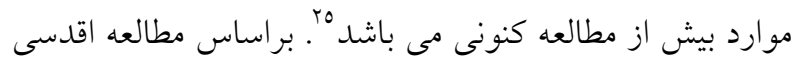

تفكيك در مبدا، به شكل دستى انجام شده و مو اد جدا شده

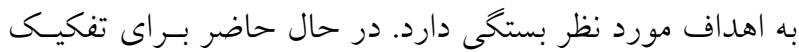

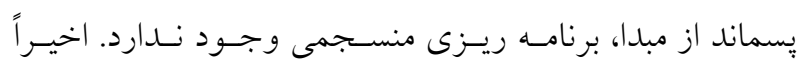

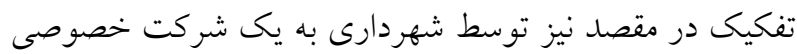

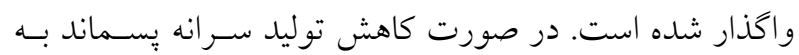

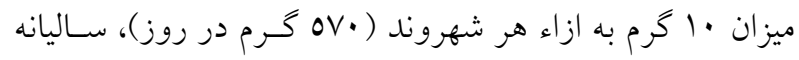

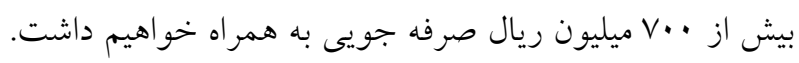

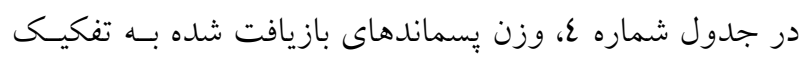

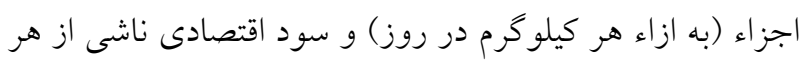

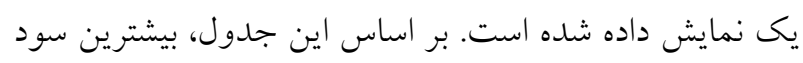

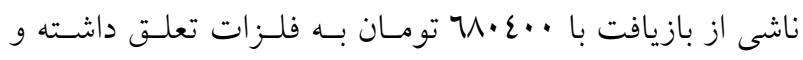

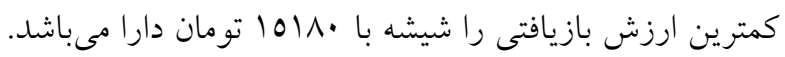
براساس تجارب حاصله، روش دفن بهداثتى اقتصادىترين و قابل قبول ترين روش دفع مواد زايد جامد به حساب مى آيد.

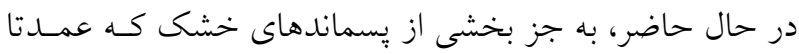
به صورت غير بهداشتى و بدون برنامه ريزى بازيافت مى شود،

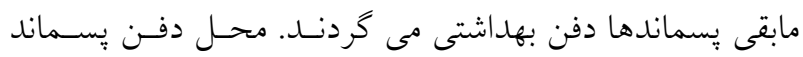

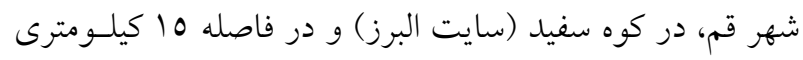

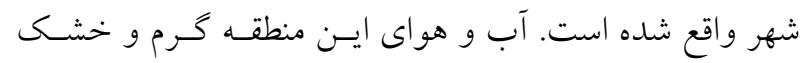

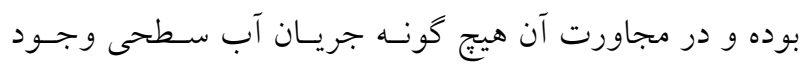

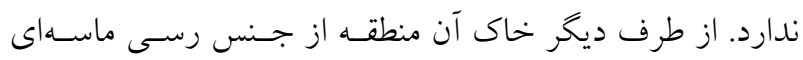

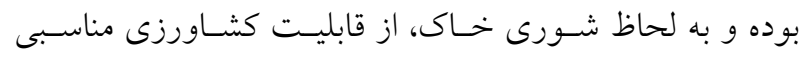

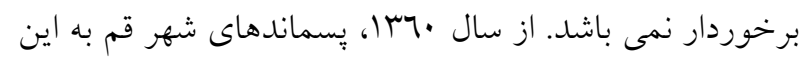

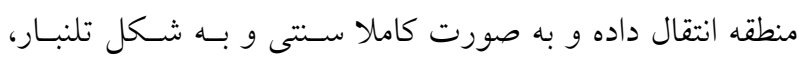

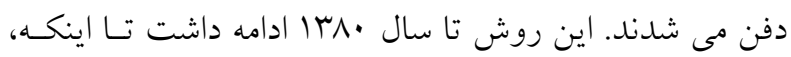

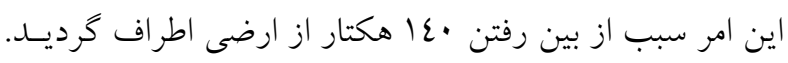

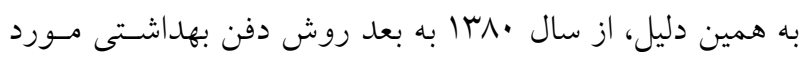




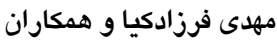

دارند. بنابر اين با يك برنامـه ريـزى صـيح و فرهنـى سـازى مناسب در امر تفكيك از مبدا مى توان از اين سود نسبتا زيـادى بهره مند شد. در تحقيقى كـه در سـال r..r در كشـور تركيسه

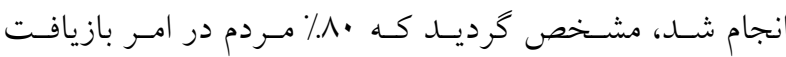

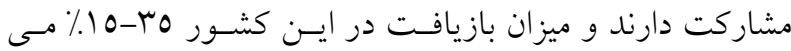
باشد كه با نتـايج حاصـل از ايـن مطالعـه مطابقـت داردهV. در مجموع، قسمت عمده مشكلات مديريت يسـماند در شهـر قـم به عدم وجود الكوى مصرف، تمايل روز افزون شهـروندان بـهـ

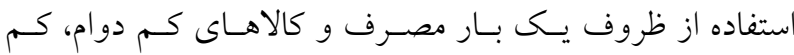

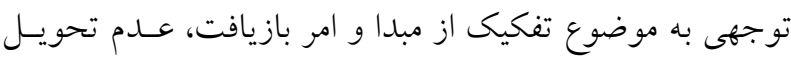

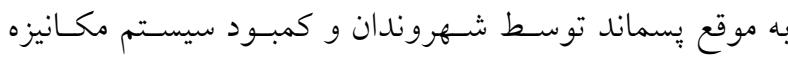

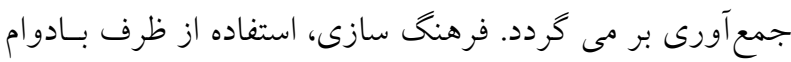

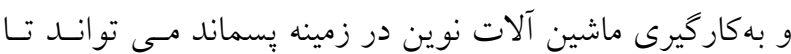
حدودى اين مشكلات را مرتفع سازد.

\section{نتيجه گيرى}

نتايج مطالعه حاضر نشان دهنده موارد زير مى باشد:

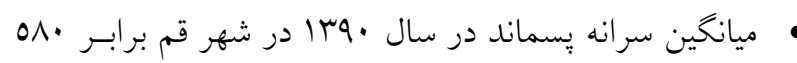

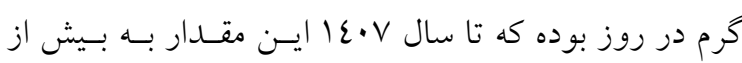
.

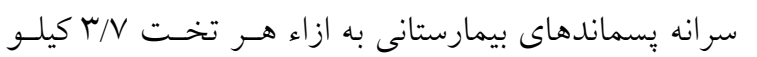
كرم مى باشد.

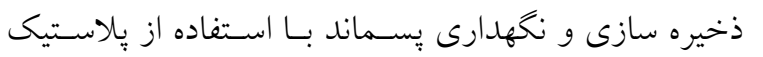
هاى مشكى رويوش شده انجام مى كيرد.

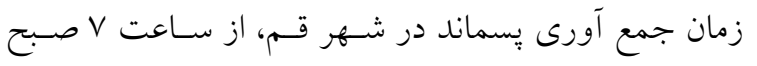

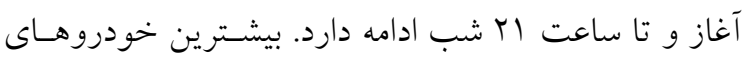

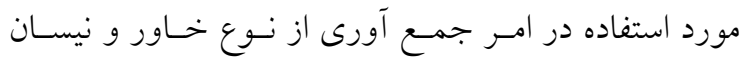

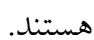
•تعداد ايستخاه هاى انتقال ع عدد مى باشد كه هنوز به شكل

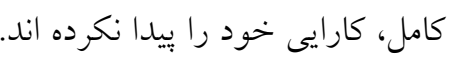

و همكاران ، درصد وزنى مواد فسـاد يـذـير، كاغـذ، هِلاسـتيك،

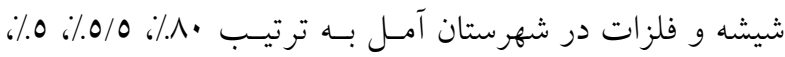

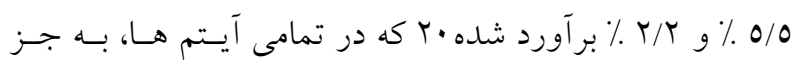
ميزان مِاستيك، مقدار بيشترى را به خود اختصاص داده اسـت.

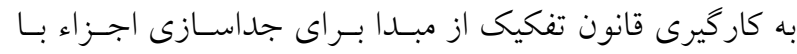
ارزش از يسماند در اين كشور، علت اصلى تفـاوت در ايـن دو

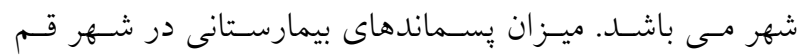
برابر “.عـ كيلو كرم در روز مى باشد كه از متوسط ميزان توليـــ

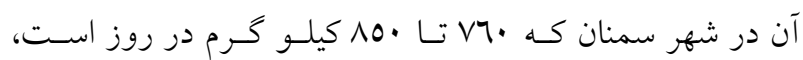

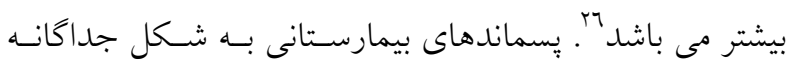

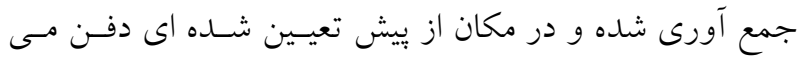

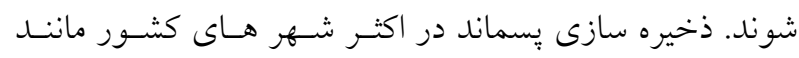

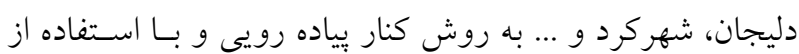

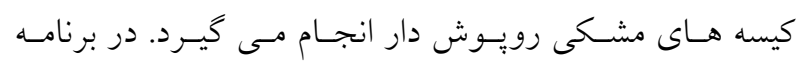

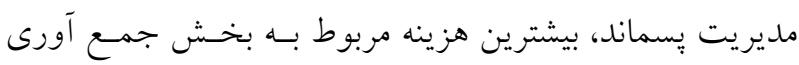

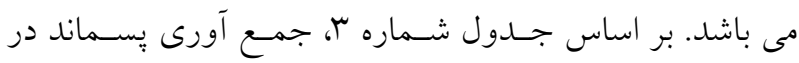

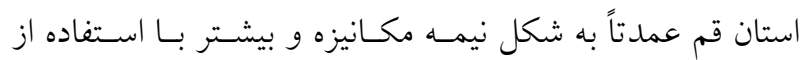

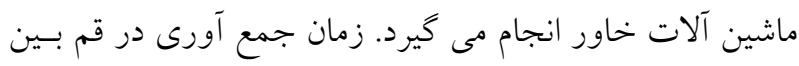

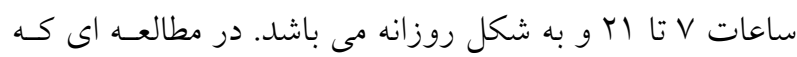

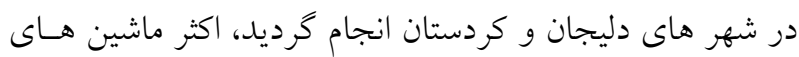

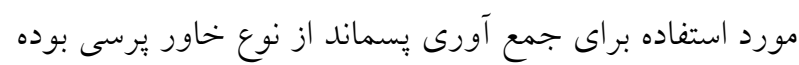

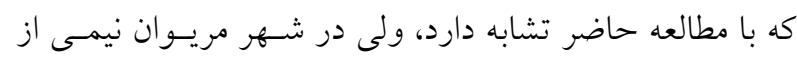

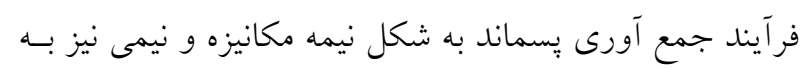

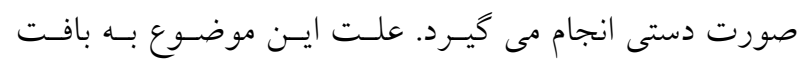

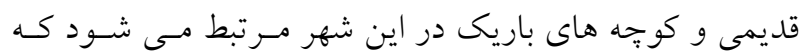

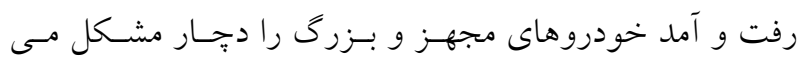
نمايد. طرح تفكيكى از مبـدا در بخشسى از شـهر قـم در حسال

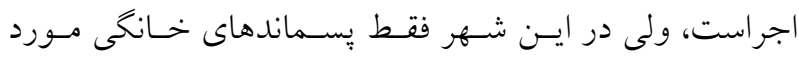

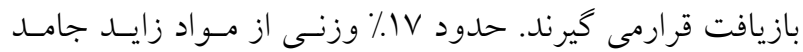

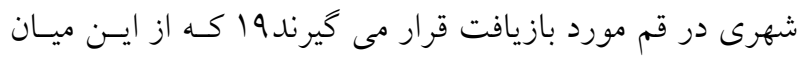
فلزات، بيشترين سود اقتصادى را براى شهردارى ها بـه همــراه 


\section{تشكر و قدردانى}

اين مطالعه با همكارى و مساعدت دانشخاه علوم يزشكى تهران

و شركت مديريت يسماند شهر قم انجام گرديــده اسـت. بـــين

وسيله نويسند كان اين مقاله، مراتب تقدير و تشكر خــود را بــه

خاطر همكارى صميمانه اين مراكز در انجام اين مطالعـه اعـلام

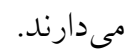

1. Yusefi S, Noroozian S. Status of solid waste management in the Chahar Mahal Bakhtiari. Sixth Congress of Waste Management; Mashhad, 2012 [In Persian].

2. Farzadkia M, Soltani M, Dalvand A. Quality and quantity of Waste production in the Delijan city. Twelveth National Conference on Environmental Health; Tehran. University of Medical Sciences Shahid Beheshti University School of Public Health. 2009 [In Persian].

3. Smaei MR, Ebrahimi A, Karimi B, Rahimi S, Bakhsgi T. Knowledge, Attitude and solid waste management in Tabas. Twelveth National Conference on Environmental Health; Tehran. University of Medical Sciences Shahid Beheshti University School of Public Health. 2009 [In Persian].

4. Ahmadi-Moghadam M, Mokhtarani N, Mokhtarani B. Municipal solid waste management in Rasht City, Iran. Waste Manage 2009;29(1): 485-9.

5. Omrani QA, Alavi-Nakhjavani N. Solid waste (recycling). 2ed. Iran: Andishe rafi. 2009 [In Persian].

6. Vaziri S. Status of solid waste management in the Kermanshah city. Proceedings of the Sixth Conference on Environmental Health. 2001 [In Persian].

7. Hasanvand M, etal .Analysis of Municipal Solid Waste. J Environ Sci Res Soc 2001;18: 1-9 [In Persian].

8. Lachynani $\mathrm{D}$, etal. A new experience in waste management casestudy of 72 villag for Isfahan city. Twelveth Conference on Environmental Health; Shahid Beheshti University of Medical Sciences. 2009 [In Persian].

9. Troschinetz AM, Mihelcic JR. Sustainable recycling of municipal solid waste in developing countries. Waste Manage 2009;29(2): 915-23.

10. Wang H, Nie Y. Municipal solid waste characteristics and management in China. J Air Waste Manage Assoc 2001;51(2): 250-63.

11. Zazuli MA, Bazrafshan I. A Comprehensive Textbook of Environmental Pollution. $1^{\text {st }}$ ed. Iran, Tehran: Samt. 2009 [In Persian].

12. Henry JG, Heineke GW. Environmental science and engineering. Environment International. 1996;6(22): 764

$$
\begin{aligned}
& \text { •IV يسماندهاى قم قابليت بازيافت دارند كه از ايـن بـين، }
\end{aligned}
$$

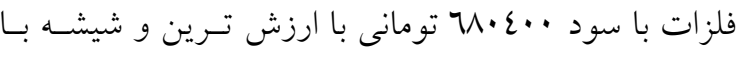

$$
\begin{aligned}
& \text { سود ••1011 تومانى كم ارزش ترين مواد قابـل بازيافت را } \\
& \text { تشكيل مى دهند. } \\
& \text { دفع يسماند نيز در شهر قم از نوع دفن بهاشتى مىباشد. }
\end{aligned}
$$

13. Omrani QA. Solid Waste. Tehran Academic Publishing Center of Islamic Azad University: Tehran. 1998 [In Persian].

14. Farzadkia M, Jorfi S, Ravanipoor M. Evaluation of Waste Management in Tehran. Iran Horizon 2009.

15. Parvaresh AR, Rafiee M, Mohammadi MJ, Fathi F. Status of collection, transportation and disposal of solid waste in the Isfehan in 1385. Eleventh National Conference on Environmental Health; Zahedan 2008; 7-9.

16. Rezaei R ,Maleki A, ZandSalimi Y, AliAbadi M, Safari M, Mahmoudi H. Study of urban waste management Saghez city And evaluation of the environment. Eleventh National Conference on Environmental Health; Zahedan 2008; 7-9.

17. ChalbtanyMahmoudi S, Sadeghi M, Banaei B. Evaluation of municipal solid waste management systems to provide management model. Eleventh Conference on Environmental Health; Zahedan 2008; 7-9.

18. Ansari H, KordMostafaPour F, Rakhshani F, Masoudi G, NaseriRad Z, Valipoor M. Knowledge and attitudes of women about recycling of solid waste in region Zahedan 1386. Eleventh national Conference on environmental Health; Zahedan 2008; 7-9.

19. Abdoli M, etal. Waste Management in Marivan (Kurdistan) City. Fifth Congress of Civil Engineering ; Ferdosi University of Mashhad 2010.

20. Amuei A, etal. Qualitative and quantitative characterization of solid wastes in Babolsar. Sixth Conference on Waste Management; Mashhad 2012.

21. SaiahZade AH, Samadi MT, . Qualitative and quantitative analysis of municipal waste Malayer from Fall 2007 to Summer 2008 iran, health and the environment.

22. Mohammadi MJ, FallahHydrmah M, Safari H, Mehrabi A. Municipal Solid Waste Management Case Study of health indicators in $\wedge r_{\text {cities in Isfahan province. Twelfth }}$ National Conference on Environmental Health; Tehran University of Medical Sciences.Faculty of Medicine Shahid Beheshti. 2009.

23. MuharramNejad N, Omrani QA, Javid AH, Mostafaei GR, Akbari $\mathrm{H}$. Investigation of the composition and quantity of solid waste produced in Kashan in 1388. Feiz. 2009;3. 


\title{
Survey the Waste Management of Qom City in 2014
}

\author{
Mahdi Farzadkia ${ }^{1}$, Hossein Azari ${ }^{* 2}$, Ehsan Ahmadi', Babak Kakavandi ${ }^{3}$, \\ Emad Dehghanifard ${ }^{4}$, Shahram Nazari ${ }^{1}$ \\ 1. Department of Environmental Health Engineering, School of Health, Iran University of Medical Sciences, Tehran, Iran \\ 2. Department of Public Administration, School of Management, University of Tehran, Tehran, Iran \\ 3. Department of Environmental Health Engineering, School of Health, Jundishapur University of Medical Sciences, Ahvaz, Iran \\ 4. Department of Environmental Health Engineering, School of Health, Alborz University of Medical Sciences, Karaj, Iran
}

"E-mail: hossein.azari@ut.ac.ir

Received: 17 Jan 2015 ; Accepted: 10 May 2015

\begin{abstract}
Background and objectives: Lack of proper management, increasing waste production and non-normative disposal of waste in addition to misspend the national capital, cause loss of precious natural resources. To address this problem we need a coherent and dynamic management program. The goal of this project is to reduce environmental pollution, cost saving, promoting citizen participation, revenue and reduce land loss.
\end{abstract}

Methods: In this study, check lists, interviews and field report were used to collect data at period of one year. To determine the waste components, sampling technique was used then sampling data was imported into Excel software and was analyzed.

Results: At the beginning of the project, the average per capita of generated waste was $580 \mathrm{~g} / \mathrm{day}$ and at the end of the project will $660 \mathrm{~g} /$ day. The waste materials determined as $\% 66.8$ putrescible, $\% 4.3$ paper and cardboard, $\% 7.2$ plastic, $\% 2.3$ glass, $\% 2$ textiles, $\% 0.2$ metals, $\% 1.6$ wood, and also, hospital waste was equal to $4400 \mathrm{Kg}$. According to estimates made annual cost of solid waste management services per capita in Qom is 70 Rial and the cost of collection, transportation, separation and disposal of garbage for every Kilogram per day is 280 Rial.

Conclusion: Amount of waste per capita in Qom was less than of Tehran, Delijan and Mallayer cities, and more than Esfahan and Kashan cities. Hospital waste was desirable as compared to the average of Iran.

Keywords: Waste Management, Qualitative and Quantitative Analysis, Solid Waste, Qom City 